УДК 37.026 .5

\title{
КОНСПЕКТ ДНЯ - УЧИМСЯ УЧИТЬСЯ ПРОДУКТИВНО В ЦИФРОВОЙ ОБРАЗОВАТЕЛЬНОЙ СРЕДЕ
}

\author{
Тихоновецкая Инга Петровна \\ ГУО «Средняя школа № 111 г. Минска» \\ магистрант «ЭОТ» ИФТИС МПГУ \\ Научный руководитель: Вайндорф-Сысоева Марина Ефимовна \\ доктор пед. наук, доцент/ профессор кафедры технологии \\ и профессионального обучения ИФТИС МПГУ
}

\begin{abstract}
Аннотация: организация учебного сотрудничества в цифровой образовательной среде с использованием приема «Конспект дня» показала свою эффективность. Совместное применение в учебном процессе приема «Конспект дня» в виде интеллект-карт, созданных в coggle.it, дает возможность обучающимся более качественно освоить лекционные материалы.
\end{abstract}

Ключевые слова: конспект дня, учебное сотрудничество, цифровые технологии, гибридное обучение, смешанное обучение, цифровая образовательная среда.

\section{SUMMARY OF THE DAY - LEARNING TO LEARN PRODUCTIVELY IN A DIGITAL EDUCATIONAL ENVIRONMENT}

\section{Tikhonovetskaya Inga Petrovna Scientific supervisor: Weindorf-Sysoeva Marina Efimovna}

\begin{abstract}
: the organization of educational cooperation in the digital educational environment using the "Summary of the day" technique has shown its effectiveness. Joint application in the educational process of the "Summary of the day" reception in the form of intelligence cards created in coggle.it, gives students the opportunity to master lecture materials more efficiently.
\end{abstract}

Keywords: summary of the day, educational cooperation, digital technologies, hybrid learning, blended learning, digital educational environment.

Исходя из сложившейся образовательной ситуации в условиях неопределенности, учебное сотрудничество в цифровой образовательной среде выступает неотъемлемым компонентом современных уроков. Цифровые 
инструменты, которые использует педагог, позволяют вовлечь обучающихся в совместную учебную деятельность. В ситуации активного взаимодействия обучающиеся уже не выступают объектом обучения, а становятся активным участником образовательного процесса.

Организуя учебное сотрудничество в ЦОС и ориентируясь на высокие учебные достижения в качестве системообразующего фактора совместной деятельности, педагог предлагает обучающимся создавать совместный «конспект дня».

Процесс управления знаниями обучающихся в цифровой образовательной среде является сложной многомерной системой, включающей целый ряд взаимосвязанных компонентов таких, как констатирование темы; определение цели и прогнозируемого результата; в зависимости от поставленных задач, определяется инструментарий для выполнения учебных заданий.

В условиях дистанционного или гибридного обучения особо остро встает вопрос организации учебного сотрудничества. Важность внедрения технологии учебного сотрудничества в ЦОС заключается в том, что педагогу необходимо создать такие условия для обучающегося, при которых в полной мере раскроется потенциал каждого.

Интересное решение для организации продуктивного взаимодействия между студентами, в частности между магистрантами, предложила Марина Ефимовна Вайндорф-Сысоева [1]. Совместное фиксирование материалов лекций с использованием приема «Конспект дня». Это специальным образом представленная значимая и важная учебная информация в различных нелинейных формах. Например, визуализированная в виде плаката, таблицы, схемы или интеллект-карты. Предполагается работа как в электронном, так и бумажном виде. Кроме представленных характеристик, важным признаком приема «Конспект дня» выступает открытость и доступность материалов, а также возможность совместного использования «наработок» каждым членом группы сотрудничества. Это возможность с разных сторон рассмотреть учебную тему. Согласитесь, что каждый по-разному воспринимает информацию, по- разному ее интерпретирует. Бывает пропускает что-то существенное. Поэтому, доступность материалов сокурсников, расширяет наши возможности и позволяет более глубоко погрузиться в тему.

В зависимости от поставленной дидактической цели и прогнозируемого результата для создания конспекта дня можно рассмотреть различные варианты цифровых решений (табл. 1) 
Таблица 1

Варианты цифровых решений

\begin{tabular}{|c|c|c|}
\hline Дидактическая цель & Результат & Инструмент \\
\hline \multirow{5}{*}{$\begin{array}{l}\text { Создание комплексного } \\
\text { конспекта } \\
\text { слушателями/студентами } \\
\text { курса }\end{array}$} & $\begin{array}{l}\text { Коллекция ссылок на конспект в } \\
\text { форуме, с возможностью открытого } \\
\text { просмотра }\end{array}$ & $\begin{array}{l}\text { Moodle } \\
\text { https://moodle.org/ }\end{array}$ \\
\hline & $\begin{array}{l}\text { Коллекция конспектов дня на } \\
\text { совместных онлайн-досках в Интернете }\end{array}$ & $\frac{\underline{\text { https://padlet.com/ }}}{\underline{\text { https://trello.com/ }}}$ \\
\hline & $\begin{array}{l}\text { Встраивание и публикация «Конспекта } \\
\text { дня» в форме интеллект-карты в } \\
\text { блоги/сайты, используя код } \\
\text { <iframe...iframe> }\end{array}$ & $\begin{array}{l}\text { Любой конструктор сайтов, } \\
\text { например, } \\
\text { https://ru.wix.com/ } \\
\underline{\text { https://www.weebly.com/ }} \\
\underline{\text { https://tilda.cc/ru/ }} \\
\underline{\text { https://sites.google.com }}\end{array}$ \\
\hline & Публикация в соцсети & $\begin{array}{l}\text { https://www.facebook.com/ } \\
\text { https://twitter.com/ }\end{array}$ \\
\hline & Конспект аналог бумажного & Сохранение в формате .pdf,.jpg \\
\hline \multirow{2}{*}{$\begin{array}{l}\text { Генерирование идей и } \\
\text { совместная работа над } \\
\text { созданием одного общего } \\
\text { «Конспекта дня» }\end{array}$} & $\begin{array}{l}\text { Конспект с общим доступом для } \\
\text { соавторов }\end{array}$ & https://coggle.it/ \\
\hline & $\begin{array}{l}\text { Организация работы с научной } \\
\text { литературой }\end{array}$ & $\underline{\text { https://coggle.it/ }}$ \\
\hline \multirow{2}{*}{$\begin{array}{l}\text { Подготовка к } \\
\text { семинарам/выступлениям/през } \\
\text { ентациям }\end{array}$} & $\begin{array}{l}\text { Фиксирование основных } \\
\text { моментов/реперных точек }\end{array}$ & https://coggle.it/ \\
\hline & $\begin{array}{l}\text { Визуализация большого объема } \\
\text { материала и демонстрация зависимости } \\
\text { одного элемента от другого }\end{array}$ & https://coggle.it/ \\
\hline
\end{tabular}

Формат представления конспекта дня разнообразен, что позволяет нашему мозгу переключиться и делает восприятие информации более интересным. Ведь наш мозг не любит однообразие.

Такое учебное сотрудничество, где каждый открывает доступ к своей работе и имеет возможность посмотреть работу другого проанализировав зафиксированный учебный материал, усиливает восприятие информации.

Дидактические цели организации такого формата взаимодействия могут быть различны (рис 1.) 
AMAAKTULECKAS

LEAB

Создание
комплексного
конспекта
слушателями/
студентами курса

\begin{tabular}{|c|c|c|}
\hline $\begin{array}{l}0 \\
1\end{array}$ & $\begin{array}{l}\text { КОЛЛЕКЦИЯ ССЫЛОК НА } \\
\text { КОНСПЕКТЫ В ФОРУМЕ } \\
\text { С ВОЗМОЖНОСТЬЮ } \\
\text { ОТКРЫТОГО ПРОСМОТРА }\end{array}$ & $\begin{array}{l}\text { Moodle } \\
\text { https://moodle.orgL }\end{array}$ \\
\hline $\begin{array}{l}0 \\
2\end{array}$ & $\begin{array}{l}\text { КОЛЛЕКЦИЯ } \\
\text { КОНСПЕКТОВ ДНЯ, } \\
\text { ОПУБЛИКОВАННЫХ НА } \\
\text { СОВМЕСТНЫХ ОНЛАЙН- } \\
\text { ДОСКАХ }\end{array}$ & $\begin{array}{l}\text { Онлайн-доски } \\
\text { https://padlet.com/ } \\
\text { https://trello.com/ } \\
\text { https://miro.com/ }\end{array}$ \\
\hline $\begin{array}{l}0 \\
3\end{array}$ & $\begin{array}{l}\text { ВСТРАИВАНИЕ И ПУБЛИКАЦИЯ } \\
\text { «КОНСПЕКТА ДНЯ» В ФОРМЕ } \\
\text { ИНТЕЛЛЕКТ-КАРТЫ В БЛОГИ/ } \\
\text { САЙТЫ, ИСПОЛЬЗУЯ КОД } \\
\text { <ІFRAМЕ...ІFRAMЕ> }\end{array}$ & $\begin{array}{l}\text { Любой конструктор сайтов, } \\
\text { например, } \\
\text { https://ru.wix.com/ } \\
\text { https://www.weebly.com/ } \\
\text { https://tilda.cc/ru/ }\end{array}$ \\
\hline $\begin{array}{l}0 \\
4\end{array}$ & $\begin{array}{l}\text { ПУБЛИКАЦИЯ ССЫЛКИ В } \\
\text { СОЦСЕТИ В ЗАКРЫТЫХ И } \\
\text { ОТКРЫТЫХ ГРУППАХ }\end{array}$ & $\begin{array}{l}\text { Популярные соцсети } \\
\text { https://www.facebook.com/ } \\
\text { https://twitter.com/ }\end{array}$ \\
\hline $\begin{array}{l}0 \\
5\end{array}$ & $\begin{array}{l}\text { КОНСПЕКТ АНАЛОГ } \\
\text { БУМАЖНОГО }\end{array}$ & $\begin{array}{l}\text { Сохранение интеллект-карты } \\
\text { в формате .pdf,.jpg }\end{array}$ \\
\hline
\end{tabular}

\section{Рис 1. Дидактические цели, результат, инструмент}

Организация продуктивного сотрудничества через генерацию идей при создании общего «Конспекта дня» (рис 2.)

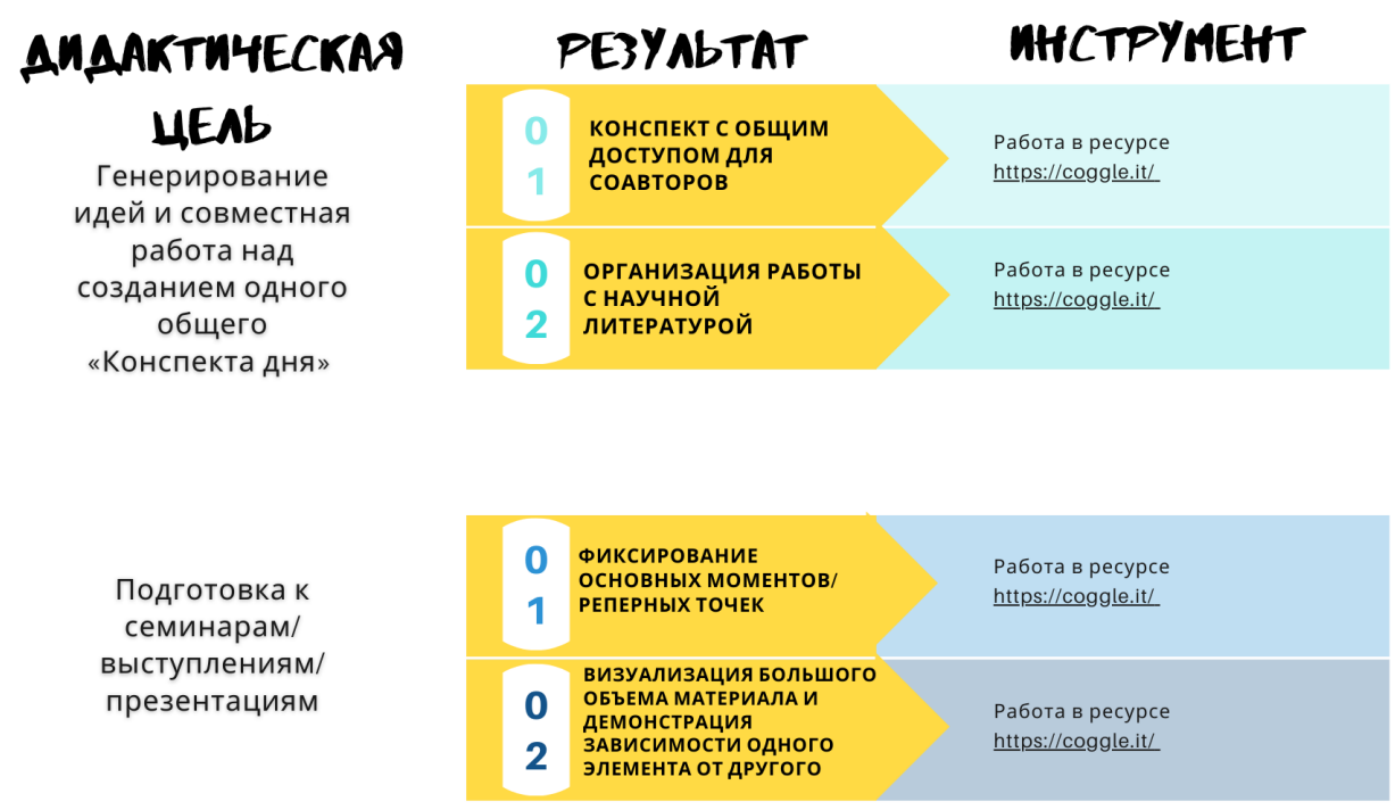

\section{Рис. 2 Дидактические цели, результат, инструмент}

Одной из популярных форм представления «Конспекта дня» является интеллект-карта. (табл.2). Техника составления интеллект-карт доказала, что служит не только отличным способом ведения записей, но и представляет собой эффективный инструмент мышления. 
Таблица 2

\section{Прием «Конспект дня» с применением ЦОР Coggle.it}

\begin{tabular}{|c|c|}
\hline Описание цифрового ресурса & $\begin{array}{l}\text { https://coggle.it/ цифровой ресурс для создания интеллект-карт. } \\
\text { Особенности: } \\
\text { • } \quad \text { несколько стартовых точек; } \\
\text { • } \\
\text { объединение ветвей в петли; } \\
\text { отображения изменений вносимых в интеллект-карту; } \\
\text { в } \\
\text { встраивание через код на сайт. } \\
\text { Почему рекомендую: } \\
\text { • } \\
\text { интуитивно понятный интерфейс и навигация; } \\
\text { в } \\
\text { возможность совместной работы; } \\
\text { н } \\
\text { неограниченное количество публичных диаграмм; } \\
\text { внтеллект-карты из доступных коллекций; } \\
\text { • } \\
\text { вагрузка и публикация фото и видео; } \\
\text { сохранение в формате .jpg, .pdf }\end{array}$ \\
\hline $\begin{array}{l}\text { Используемые методы при } \\
\text { решении дидактической задачи }\end{array}$ & $\begin{array}{l}\text { • } \\
\text { Общедидактические методы } \rightarrow \text { проблемный, } \\
\text { • } \quad \text { Метод активного взаимодействия (с проведением учебных } \\
\text { коллективных дискуссий) } \rightarrow \text { дискуссия. } \\
\text { • } \quad \text { Метод ситуационного анализа. } \\
\text { Организации взаимодействия обучаемого с образовательными } \\
\text { ресурсами } \rightarrow \text { «кейс-технология». } \\
\text { • } \quad \text { Интерактивные методы } \rightarrow \text { мозговой штурм, работа в группах, } \\
\text { ролевая игра, разработка проекта, интервью, просмотр и обсуждение } \\
\text { видеофильмов, презентации с использованием различных } \\
\text { вспомогательных средств. }\end{array}$ \\
\hline $\begin{array}{l}\text { Педагогические технологии, где } \\
\text { может быть использован прием } \\
\text { «Конспект дня» }\end{array}$ & 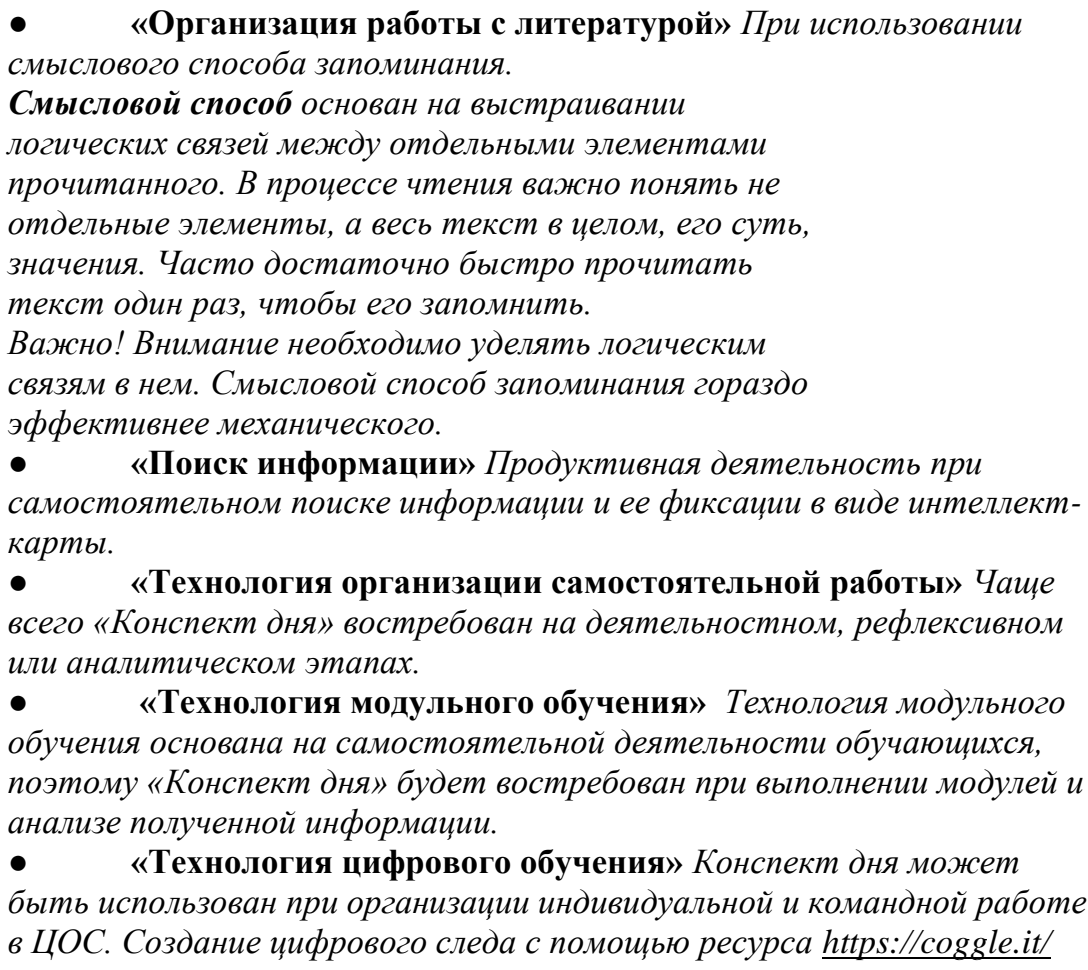 \\
\hline Примеры & 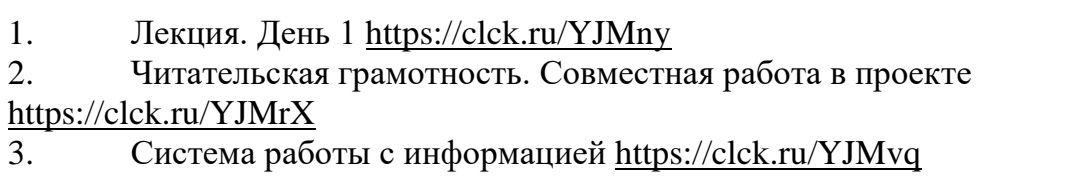 \\
\hline
\end{tabular}


Полученный опыт организации учебного сотрудничества с использованием приема «Конспект дня» в условиях дистанционного или гибридного обучения показал свою эффективность. Эффективность заключается, в первую очередь, в более полном и целенаправленном использовании образовательного потенциала конкретных цифровых решений для решения конкретных дидактических задач, а также к повышению мотивации обучающихся к применению инновационных технологий и возможностью построения и реализации индивидуальных образовательных траекторий.

На наш взгляд, совместное применение в учебном процессе интеллекткарт, созданных в coggle.it, расширяет рамки обычных занятий, предоставляя обучающимся больше возможностей для переосмысления лекционных материалов.

\section{Список литературы}

1. Вайндорф-Сысоева, М. Е. Конференция о влиянии цифровых следов на качество образования «Практика применения цифрового следа в образовательном процессе». Изображение (движущееся ; двухмерное): видео. URL: https://youtu.be/LuQjve81V88?t=6934 (дата обращения: 18.10.2021).

2. Веленский В. Я., Образцов П. И., Уман А. И. Технология профессионально - ориентированного обучения в высшей школе: Учебное пособие. М.: Педагогическое общество России, 2005.

3. Дьяченко Наталья Васильевна Методические особенности подготовки лекции в вузе // Концепт. 2019. №V1. URL: https://cyberleninka.ru/article/n/metodicheskie-osobennosti-podgotovki-lektsii-vvuze (дата обращения: 06.04.2021).

4. Жилина, А. И. Системно-деятельностный подход к управлению знаниями на уроке в соответствии с требованиями ФГОС / А. И. Жилина // Человек и образование. - 2017. - № 4(53). - С. 59-63.

5. Киреева Зоя Алексеевна Особенности подготовки и использования проблемной лекции в вузе // Вестник Курганского государственного университета. 2013. №4 (31). URL: https://cyberleninka.ru/article/n/osobennostipodgotovki-i-ispolzovaniya-problemnoy-lektsii-v-vuze (дата обращения: 05.04.2021).

6. Тихоновецкая, И. П. Дистанционное обучение школьников во время карантина / И. П. Тихоновецкая - Текст : непосредственный // Пачатковае 
навучанне: сям'я, дзіцячы сад, школа. Сер., "У дапамогу педагогу" : навуковаметадычны часопіс. - 2020. - № 11. - С.1-8. - Прил. к журналу : Университет педагогического мастерства. - ISSN 1993-2677

7. Тихоновецкая, И.П. Формирование читательской грамотности у младших школьников с использованием ИКТ / И. П. Тихоновецкая, Н.Д. Вьюн - Текст : непосредственный // Пачатковае навучанне: сям'я, дзіцячы сад, школа. Сер., "У дапамогу педагогу" : навукова-метадычны часопіс. - 2021. - № 4. C.1-16.. - Прил. к журналу : Университет педагогического мастерства. - ISSN 1993-2677

() И. П. Тихоновецкая, 2021 